Disponível em:

http://editora.unoesc.edu.br/index.php/race

Race, Joaçaba, v. 15, n. 2, p. 579-600, maio/ago. 2016

\title{
MODELAGEM ESTATÍSTICA COM FOCO NA MOTIVAÇÃO DOS BANCOS QUE SECURITIZARAM NO BRASIL ENTRE OS ANOS DE 2005 E 2012
}

Statistical model focused on the motivation to securitization of banks in Brazil between the years of 2005 and 2012.

Cristina Ferabolli

E-mail: crisferabolli@yahoo.com

Mestre em Economia pela Università degli Studi di Napoli Federico II - Itália; Especialista em MBA em Finanças e Controladoria pela Fundação Getúlio Vargas.

Igor Alexandre Clemente Morais

E-mail: igoracmorais@gmail.com

Doutor e Mestre em Economia pela Universidade Federal do Rio Grande do Sul; Professor de Graduação e Pós-Graduação na Universidade do Vale do Rio dos Sinos. Endereço para contato: Avenida Unisinos, 950, Cristo Rei, 93022-000, São Leopoldo, Rio Grande do Sul, Brasil.

Artigo recebido em 25 de maio de 2015. Aceito em 30 de março de 2016. 
Resumo

Nesta pesquisa teve-se como objetivo analisar os principais fatores que levaram os bancos brasileiros a utilizarem instrumentos de securitização no período de 2005 a 2012. Avaliouse, ainda, o cenário da crise financeira global de 2007 a 2008 e se esta modificou o padrão da securitização no mercado brasileiro. Os resultados obtidos para uma amostra de 643 observações indicam que a liquidez é o fator determinante na opção pela securitização, seguido pelo capital regulatório. Além disso, o tamanho do banco também apresenta relevância estatística, sinalizando possíveis ganhos de escala nas operações de securitização. Não foram encontradas evidências de utilização da securitização por transferência de risco de crédito e por performance, nem de mudanças no padrão da securitização, no Brasil, no período pré e pós-crise.

Palavras-chave: Securitização. Liquidez. Capital regulatório. Risco de crédito.

\section{Abstract}

In this research the aim was to analyze the main factors leading Brazilian banks to use securitization instruments in the period of 2005-2012. It was also evaluated the scenario of the global financial crisis of 2007-2008 and whether it changed the pattern of securitization in Brazil. The results using a sample of 643 observations indicate that liquidity is the main determining factor in the choice of securitization, followed by regulatory capital. Moreover, the size of the bank also presents statistical relevance, signaling possible economies of scale in securitization transactions. There is no evidence of the use of securitization for credit risk transfer and performance, nor evidence of changes in the pattern of securitization, in Brazil, in the pre and post-crisis.

Keywords: Securitization. Liquidity. Regulatory capital. Credit risk.

\section{INTRODUÇÃO}

As inovações financeiras criadas a partir de 1960 contribuíram para uma melhor gestão de caixa de empresas e investidores, mas também abriram espaço para uma maior integração global. Uma das mais importantes e que passou a ser largamente utilizada no setor bancário foi a securitização. Com essa ferramenta iniciou-se uma nova etapa no setor bancário, na qual este ultrapassou o limite de oferta de recursos apenas com os depósitos. Tal mudança possibilitou a criação de diferentes fontes de financiamento, beneficiando a gestão de risco de crédito e facilitando o cumprimento de exigências de capital regulatório; além disso, aumentou a liquidez, permitiu maior 
diversificação de portfólios e uma melhor gestão de ativos e passivos (CEBENOYAN; STRAHAN, 2001; LOUTSKINA, 2011).

Apesar da complexidade adquirida ao longo do tempo, a securitização, de forma resumida, pode ser entendida como um instrumento que permite padronizar ativos de diferentes tipos e, com isso, comercializá-los no mercado de capitais; permite que uma dívida seja convertida em títulos, que têm como lastro esses ativos e que possam, então, ser negociados entre as instituições financeiras.

A crise que atingiu o sistema financeiro internacional de 2007 a 2008 intensificou a discussão no âmbito do uso de instrumentos derivativos e, com eles, a securitização. O ponto central passou a ser a regulação que culminou com a proposta ${ }^{1}$ da Basiléia III e que prevê diversos estágios de implementação em vários países.

Uma das principais razões que fez com que a crise financeira global de 2007 a 2008 atingisse níveis tão elevados foi a utilização de alavancagem excessiva pelos bancos de vários países, em complexas operações de securitização e resecuritização dentro e fora de seus balanços patrimoniais no que ficou denominado bancos-sombra. Esse excesso de alavancagem foi acompanhado por desgastes gradativos no nível e na qualidade de capital dessas instituições ${ }^{2}$ e não tinha o correto acompanhamento dos órgãos reguladores.

No Brasil, o primeiro passo na regulação da securitização aconteceu em 1991, com a Resolução n. 1.834 do Conselho Monetário Nacional. Apesar de ainda não ser denominada securitização, a Resolução determinava a possibilidade de captação no mercado externo, com vínculo às exportações da própria tomadora ou de suas controladas. Dez anos depois, a Resolução n. 2.907/2001, do Banco Central do Brasil, versava sobre os Fundos de Investimentos em Direitos Creditórios - FIDCs. ${ }^{3}$ Este foi o primeiro instrumento criado no mercado brasileiro cujos direitos contemplam diversos segmentos distintos da economia, como o financeiro, imobiliário, o comercial, o hipotecário, o industrial, o arrendamento mercantil, a prestação de serviços, entre outros.

Considerando-se a complexidade do tema em questão, nesta pesquisa discute-se a temática relativa a produtos financeiros estruturados nos mercados de capitais no Brasil, analisando os principais fatores que levaram os bancos brasileiros a utilizarem a securitização no período de 2005 a 2012. Além disso, procura-se identificar se houve mudanças no padrão da securitização no mercado nacional no pós-crise financeira global de 2007 a 2008.

O teste de diferença de médias apontou que a liquidez, os níveis de capital regulatório e a performance são distintos entre os grupos de bancos que securitizam e os que não securitizam. As estimativas para a amostra total sinalizaram que apenas 
dois fatores podem ser considerados motivadores para a securitização no período analisado: a liquidez e o capital regulatório. Um aspecto interessante da significância do capital regulatório é que esta ocorre somente com a relação capital sobre ativos totais e não quando se considera o Índice de Basiléia. O que pode justificar esse resultado é que todos os bancos se encontravam enquadrados sob essa regra no período analisado, reduzindo-o como motivo para securitizar. Além disso, a não significância do fator performance na probabilidade de securitização pode estar ligada à alta taxa de juros e aos spreads praticados no país.

A principal contribuição desta pesquisa foi na ampliação de estudos sobre o tema securitização no setor bancário brasileiro, relacionando os ganhos possíveis com a disseminação desses produtos estruturados e os principais fatores que determinam a utilização ou não por uma instituição financeira. Além disso, esta pesquisa permitiu que estudos realizados nos mercados norte-americano e europeu fossem testados no Brasil e que resultados similares fossem encontrados, o que poderia levar a conclusões de que os mercados financeiros nacionais estão evoluindo e alcançando patamares verificados em países desenvolvidos.

Além desta introdução, este trabalho conta com mais quatro seções. Na segunda é feita uma revisão dos estudos sobre securitização, tanto na literatura internacional quanto na nacional. A seguir, na seção três, são apresentadas as variáveis e os dados utilizados. Na seção quatro é feita a análise dos principais resultados, e a última seção conclui.

\section{SECURITIZAÇÃO}

Nos produtos financeiros estruturados, há instrumentos chamados de derivativos de crédito puros e há aqueles denominados securitização, ambos utilizados para transferir o risco entre instituições financeiras, mas preservando características que os diferenciam dos demais instrumentos utilizados para esse fim. A primeira delas, comum a ambos ativos, personaliza-se na possibilidade de transformação do risco incorrido na distribuição das perdas atribuídas aos ativos utilizados como lastro, mediante a divisão desse risco em várias fatias, denominadas tranches.

As várias tranches emitidas possuem perfis distintos de risco e retorno, em que o ativo utilizado como collateral é retirado do balanço patrimonial do originador da transação. O fator-chave na criação de tranches está na habilidade em criar classes distintas de ativos que contenham um rating maior do que o rating médio dos ativos 
que foram agrupados e serviram como lastro do produto, ou, ainda, em criar ativos arriscados a partir de um grupo de ativos sem ratings a eles associados.

A característica marcante dos produtos estruturados, como os derivativos de crédito, refere-se à permanência no balanço patrimonial das instituições emissoras, não tendo impactos de redução dos requerimentos econômicos mínimos de capital. Por outro lado, os produtos de securitização transitam fora do balanço, reduzindo, assim, os custos associados aos requerimentos mínimos de capital estipulados pelas autoridades monetárias. Essa desvinculação do risco de crédito associado ao grupo de ativos utilizados como lastro é feita pela transferência do ativo subjacente para uma Empresa de Propósito Específico (SPV), criada exclusivamente para esse fim (BAUR; JOOSSENS, 2006).

Os benefícios dessa operação foram percebidos no mercado financeiro nos EUA, o maior originador e de volume de transação desse derivativo. A literatura aponta quatro fatores determinantes do avanço da transferência de risco de crédito naquele país: a redução da regulamentação de necessidade de capital para esses ativos; a possibilidade de acesso a fontes de financiamento novas e mais baratas; o gerenciamento de portfólios e a atratividade do perfil de risco e retorno envolvidos nesse tipo de transação (COMMITTEE OF THE GLOBAL FINANCIAL SYSTEM, 2005; MASON; ROSNER, 2007).

Com a ampliação no uso desse instrumento e a regulação, ocorreu a separação entre as atividades comerciais e de investimento, abrindo espaço para um significativo aumento da liquidez concomitante ao risco sistêmico. ${ }^{4}$ Em razão do impacto que a securitização tem nos bancos, é natural que estes busquem produtos estruturados por motivos que vão desde questões regulatórias de mercado, chegando a questões econômicas e contábeis específicas. Diversos autores apontam os benefícios e custos dessa operação no setor bancário, como Lee (2003), Duffie (2008), Catão, Rodrigues e Libonati (2009), Cebenoyan e Strahan (2001), Loutskina (2011) e Baur e Joossens (2006).

No Brasil, o primeiro passo no processo regulatório sobre securitização ocorreu após a Resolução do CMN n. 1.834/1991. Desde então, diversos outros instrumentos e resoluções tiveram curso. Dois importantes instrumentos financeiros tiveram rápida aceitação no Brasil nesse período, o Certificado de Recebíveis Imobiliários (CRI), e os Fundos de Investimento em Direitos Creditórios (FIDCs), notadamente a partir de 2002. Destacam-se as alterações introduzidas pela Instrução CVM n. 472/08, que permitiu a inclusão de valores mobiliários, como CRIs e quotas de FIPs e FIDCs voltados ao setor imobiliário. Outro avanço importante foi a Instrução da CVM n. 531/2013, com foco na governança, resolução de conflitos de interesse e definição de responsabilidades e controles internos. 
A literatura nacional na área é relativamente pequena e recente e esteve concentrada em estudos sobre o impacto dos FIDICs como instrumento de securitização.

Catão (2006) mostrou evidências de que a securitização piorou a qualidade de crédito da carteira dos bancos, mas melhorou a liquidez. Já Luxo (2007) evidencia que a securitização de ativos implicou a melhora do rating de crédito das empresas que a utilizam, e Pulino (2008) mostrou que a estruturação de FIDCs pode resultar na emissão de títulos securitizados com risco de crédito inferior àquele associado ao endividamento de longo prazo da empresa cedente, apesar de haver evidências de que a redução do custo de capital não é a única razão para a utilização de um FIDC.

Também há evidências no estudo de Laureano (2009), ao investigar o impacto da venda das carteiras de crédito pelas instituições financeiras brasileiras, de melhora no rating da carteira remanescente ou, então, da promoção de maior alavancagem financeira. Seus estudos mostraram evidências de que as vendas foram utilizadas para melhora do rating da carteira remanescente, ou seja, a maioria das instituições financeiras analisadas transferiram seus ativos de baixa qualidade para garantir melhores ratings e melhorar a sua liquidez.

As vantagens no uso de FIDCs como instrumento de securitização no Brasil também foram apontadas no estudo de Silva (2006), que avaliou dados de micro e pequenas empresas, e também em Pinheiro (2008), que apontou os riscos que os investidores incorrem em cotas seniores. Como estes são baixos, justificariam as elevadas classificações creditícias que as agências de rating lhes atribuem. Para o originador dos ativos, o risco de retornos inferiores à taxa de juros de mercado é também consideravelmente baixo graças ao elevado spread embutido na taxa de juros dos ativos. Complementando a literatura sobre FIDCs, Fernandes (2010) evidenciou que as empresas com piores ratings securitizam mais e que o rating das empresas influencia o spread cobrado nos FIDCs.

Por outro lado, Goldberg (2011) não encontrou suporte para o fato de que o anúncio de securitização via FIDCs teria impacto sobre o preço da ação da empresa, um resultado diferente do apontado em estudos realizados para os EUA. Por fim, Oliveira (2012) verificou que a remuneração dos FIDCs é determinada pelo rating e pelas condições de mercado, além das características do cedente que também se mostraram relevantes. A autora destacou, ainda, que a relação negativa entre o rating e o percentual de cotas subordinadas indica que os emissores definem a subordinação para obter boas avaliações.

Como pode ser visto, comparado aos mercados financeiros internacionais mais desenvolvidos, ainda existe muito espaço para o crescimento de estudos relacionados a produtos de securitização no Brasil. 
Além disso, a regulamentação dos produtos financeiros estruturados ainda sofre ajustes e evoluções, tanto no mercado nacional quanto no internacional. No mercado brasileiro, as diversas instruções e resoluções da CVM, implementadas ao longo dos mais de 20 anos de produtos de securitização, fizeram com que os volumes de emissões alcançassem patamares cada vez maiores. Soma-se a isso a evolução do arcabouço legal no âmbito da Basiléia I, II e III, que criou novas formas de mitigar riscos financeiros e operacionais, o que pode proporcionar mais transparência e segurança a esse mercado no futuro.

\section{DADOS E VARIÁVEIS}

Os dados utilizados neste estudo cobrem o mercado de securitização no setor bancário brasileiro no período de 2005 a 2012, em razão do crescimento desses instrumentos no período e da dificuldade de levantamento de dados analíticos em períodos anteriores a 2005. Para esses fins, a atividade de securitização foi definida como a cessão de créditos sem coobrigação, mesma proxy utilizada por Catão (2006) ao analisar os impactos da securitização no setor bancário brasileiro. Nesse caso, a venda dos recebíveis é caracterizada como definitiva, e o cedente dos recebíveis não terá nenhuma obrigação pelo prazo ou inadimplência que possam surgir dos recebíveis por ele cedidos (LUXO, 2007).

A amostra é composta por todos os bancos comerciais, múltiplos e cooperativos e Caixa Econômica em funcionamento em dezembro de 2012 que apresentaram informações disponíveis para todas as variáveis em análise em cada ano do estudo. Além disso, supondo a distribuição normal dos dados, foram eliminadas da amostra todas as instituições que apresentaram índices que fogem da normalidade, como valores nulos ou infinitos, considerados outliers.

Uma vez aplicados esses filtros, a amostra final consiste em 643 observações, que caracterizam atividades em um mínimo de 74 bancos (em 2007) e em um máximo de 91 (em 2012). Desse total, 548 atividades foram identificadas como pertencentes a bancos múltiplos, 71 a bancos comerciais, 16 a bancos cooperativos e 8 relativas à Caixa Econômica Federal, mas que variam de ano para ano.

Destaca-se, ainda, que um banco pode aparecer nas observações de um ano e no ano seguinte não pertencer à amostra em decorrência da indisponibilidade de dados ou determinada informação, e retornar, ou não, à amostra no ano seguinte. Assim, das 643 observações, 468 são de bancos que não tiveram nenhuma operação de securitização no período, e 175 são relativas a bancos que realizaram pelo menos uma securitização no período. 
Uma vez que o principal objetivo com esta pesquisa foi identificar os fatores que levaram os bancos brasileiros a utilizarem a securitização, a variável dependente assume valor igual a 1 , se o banco tiver securitizado pelo menos uma vez no período em análise, e igual a 0 caso não tenha utilizado a securitização no período. Em seguida, identificam-se as variáveis explicativas, que são características específicas dos bancos, visto que três fatores são os mais fortemente avaliados em estudos específicos para a identificação dos motivadores da securitização: a necessidade de novas fontes de financiamento ou liquidez, a transferência do risco de crédito e o capital regulatório. Cardone-Riportella, Samaniego-Medina e Trujillo-Ponce (2010) adicionaram um quarto fator como variável explicativa: melhora de performance para as instituições, além de elencarem uma série de variáveis de controle.

Dessa forma, a definição das variáveis segue a classificação dos fatores considerados na literatura da área. A escolha dos indicadores para compor este estudo, bem como a metodologia aplicada, basearam-se naqueles utilizados por Cardone-Riportella, Samaniego-Medina e Trujillo-Ponce (2010), adaptados aos dados disponíveis no mercado brasileiro. Os autores consideraram estudos anteriores com propósitos similares para escolher tais fatores. ${ }^{5}$

Estudos realizados em mercados internacionais, como os de Calomiris e Mason (2004), Minton Sanders e Strahan (2004), Uzun e Webb (2007), e no europeu, apresentados por Martin-Oliver e Saurina (2007), Agostino e Mazzuca (2008), Bannier e Hãnsel (2008), Cardone-Riportella, Samaniego-Medina e Trujillo-Ponce (2010) e Cerrato et al. (2012), apontam que questões relacionadas à liquidez são forte indicativos para a utilização de securitização.

Nessa linha, usam-se como Proxy três tipos diferentes de medida de liquidez:

a) Relação interbancária (L1P): relação percentual entre os volumes de empréstimos entre instituições financeiras. Se essa relação é maior do que 1 , o banco é um provedor de recursos no mercado financeiro ao invés de um tomador de empréstimos, o que o torna mais líquido. Segundo Cerrato et al. (2012), os maiores bancos no mercado financeiro mundial são tomadores de empréstimos no mercado interbancário, apresentando uma relação interbancária de 0,746, o que indica que eles dependem de bancos menores para prover os recursos necessários à suas operações de crédito;

b) Operações de crédito líquidas/Depósitos e Obrigações de Curto Prazo (L2P): a segunda proxy utilizada para a liquidez é a relação entre o total 
líquido das operações de crédito e o total de depósitos e obrigações de curto prazo. Quanto maior for essa relação, menos líquido é o banco;

c) Ativos Líquidos/Depósitos e Obrigações de Curto Prazo (L3P): neste terceiro índice, busca-se avaliar a relação entre os ativos líquidos e o total de depósitos e de obrigações de curto prazo, como forma de medir a proporção de recursos disponíveis no caso de um stress econômico fazer com que todos os clientes resolvam sacar seus recursos em determinada instituição. Quanto maior for essa relação, mais líquido é o banco e menos vulnerável a eventos clássicos de corrida a ele. Uma vez que os depósitos são, geralmente, a principal fonte dos recursos no setor bancário e podem ser sacados de forma aleatória, as instituições financeiras mantêm parte desses depósitos em ativos líquidos, reduzindo, assim, a exposição ao risco de liquidez.

O segundo fator motivador da securitização é a transferência de risco de crédito. Neste estudo, a Proxy dessa medida é a relação entre a Provisão de Crédito de Liquidação Duvidosa (PCLD) e o total de operações de crédito. Esse fator refere-se à gestão de crédito da carteira, sendo a securitização uma forma de transferência de parte do risco de crédito para outra instituição. Assim, essa relação indica o total das operações de crédito da instituição financeira que está sendo provisionada como liquidação duvidosa, expressa por uma relação percentual sobre o total das operações de crédito. Quanto maior for essa relação, menor será a qualidade da carteira de crédito da instituição e, consequentemente, maior será o risco.

O terceiro fator motivador da securitização está relacionado a questões de capital regulatório para atender às regras impostas pela respectiva Autoridade Monetária. Uma vez que a hipótese de securitização como forma de arbitragem do capital regulatório se confirme, uma instituição que tenha menos capital regulatório terá um incentivo maior para securitizar seus ativos. Isso porque esses índices sinalizam o nível de capitalização das instituições, e quanto maior for essa relação, melhor capitalizado está o banco e menor a propensão para securitizar. Além disso, as questões regulatórias não exercem pressão sobre esses índices, que já estariam acima daqueles exigidos legalmente. Nesse caso, são propostas duas medidas para esse fator: Índice de Basiléia (C1P): indica o percentual de capital regulatório necessário de acordo com as regras do acordo de Basiléia, que é calculado para cada instituição financeira como uma medida de alavancagem de capital ponderada pelo risco de crédito de suas carteiras; Capital/Ativo Total (C2P): este índice mede quanto do capital está protegido contra possíveis perdas em suas operações. Quanto maior for esse índice, melhor será 
a proteção apresentada pelo banco, uma vez que o capital da instituição serve como um amortecedor contra uma má utilização de seus ativos, e também pode ser utilizado para mostrar o quanto o banco está protegido pelo capital que nele foi investido.

Por fim, o quarto fator motivador da securitização é a melhoria de eficiência da instituição, também denominado performance. Para esse caso são propostos três tipos diferentes de medidas: Retorno sobre o ativo - ROA (P1P): importante indicador de eficiência operacional em bancos, considera o retorno gerado pelos ativos financiados pela instituição, ou seja, a relação entre o lucro líquido e o ativo total; Retorno sobre capital próprio - ROE (P2P): medido pela relação entre o lucro líquido e o capital próprio da instituição financeira, quanto maior seu valor, melhor o desempenho do banco; Índice de custo sobre a receita - CIR (P3P): mede quanto da receita gerada pela instituição é utilizada para cobrir suas despesas operacionais. ${ }^{6}$

Além dessas variáveis apontadas em cada fator, também é utilizado o tamanho do banco (TAMP), caracterizado pelo log do Ativo Total da instituição como uma variável de controle. A expectativa é que esta deve ser uma relação positiva em razão dos ganhos de escala decorrentes dos custos fixos de um programa de securitização.

\section{MODELO E ESTIMATIVAS}

Para os propósitos desta pesquisa, optou-se pelo modelo de Regressão Logística (Logit), mesmo método proposto em estudos como os de Cardone-Riportella, Samaniego-Medina e Trujillo-Ponce (2010), Cerrato et al. (2012), Bannier e Hãnsel (2008) e Uzun e Webb (2007). Dessa forma, a equação geral é dada por:

$$
Y_{i, t}=\beta_{0}+\beta_{1} L_{i, t-1}+\beta_{2} R I_{i, t-1}+\beta_{3} C A_{i, t-1}+\beta_{4} P E_{i, t-1}+\beta_{5} T A M P_{i, t-1}+\beta_{6} C R I S E_{i, t}+\epsilon_{t}
$$

Em que: $Y_{i t}$ é a variável dependente dicotômica; $L_{i, t-1}, R I_{i, t-1}, C A_{i, t-1}, P E_{i, t-1}$ são as variáveis explicativas de liquidez, risco, capital regulatório e performance incluídas no modelo, respectivamente; TAMP $_{\mathrm{i}, \mathrm{t}-1}$ é a variável de controle tamanho do banco (LN do Ativo Total); crise é uma dummy que assume valores 1 e 0 , sendo 1 o período de 2005 a 2008 (pré-crise), e 0, o período de 2009 a 2012 (pós-crise), e $\epsilon_{t}$ é o valor dos resíduos no tempo. A dummy tem como objetivo captar possíveis mudanças nos fatores motivadores da securitização no período pré e pós-crise.

Todas as variáveis entram na regressão com um período de defasagem para evitar possíveis problemas de endogeneidade. Para realizar as estimativas, a amostra foi padronizada, de forma a eliminar as diferenças de unidade de medida entre elas. 
Além disso, a amostra foi separada em dois períodos distintos: de 2005 a 2008, caracterizado como pré-crise, e de 2009 a 2012, como pós-crise.

Para ver se existe ou não diferença entre os bancos que utilizaram o instrumento de securitização no período considerado e aqueles que não o utilizaram, foi feito um teste de diferença de média, observado na Tabela 1. Os resultados mostraram que os indicadores de liquidez, capital regulatório e, com menor significância estatística, o fator performance, são diferentes. Vale destacar que esse resultado não comprova que a origem da diferença dos indicadores ocorre pela securitização, apenas que os grupos se diferenciam.

Tabela 1 - Anova - Teste entre os bancos que securitizaram e não securitizaram

\begin{tabular}{lll}
\hline Variáveis & Estatística F & P-valor \\
\hline Relação interbancária (L1P) & 6.184028 & $0.0131^{*}$ \\
Operações de crédito líquidas/Depósitos e obrigações de C.P. (L2P) & 0.795586 & 0.3728 \\
Ativos líquidos/Depósitos e obrigações de C.P. (L3P) & 14.46374 & $0.0002^{*}$ \\
\hline PCLD/Total de operações de crédito (R1P) & 1.000409 & 0.3176 \\
\hline Índice de Basiléia (C1P) & 5.071122 & $0.0247^{*}$ \\
Capital/Ativo total (C2P) & 1.258944 & 0.2623 \\
\hline ROA (P1P) & 0.469580 & 0.4934 \\
ROE (P2P) & 0.032757 & 0.8564 \\
CIR (P3P) & 3.182816 & $0.0749^{* *}$ \\
\hline Tamanho (TAMP) & 3.005979 & $0.0834^{* *}$ \\
\hline
\end{tabular}

Fonte: os autores.

Nota:* Estatisticamente significante ao nível de 5\%. ** Estatisticamente significante ao nível de $10 \%$.

A correlação de Pearson entre as variáveis da amostra é baixa, conforme se observa na Tabela 2 e, em muitos casos, próxima a zero, resultado importante para evitar erro de especificação do modelo.

Tabela 2 - Correlação entre as variáveis independentes

\begin{tabular}{|c|c|c|c|c|c|c|c|c|c|}
\hline Variáveis & L1P & L2P & L3P & R1P & C1P & $\mathrm{C} 2 \mathrm{P}$ & $\mathrm{P} 1 \mathrm{P}$ & $\mathrm{P} 2 \mathrm{P}$ & P3P \\
\hline L2P & 0.0741 & & & & & & & & \\
\hline L3P & -0.1150 & 0.0959 & & & & & & & \\
\hline R1P & 0.0024 & -0.0086 & 0.1050 & & & & & & \\
\hline C1P & -0.0585 & -0.0422 & 0.4199 & 0.1829 & & & & & \\
\hline $\mathrm{C} 2 \mathrm{P}$ & -0.0558 & -0.0358 & 0.4627 & 0.1652 & 0.5107 & & & & \\
\hline P1P & -0.0337 & 0.0073 & 0.0092 & 0.0112 & 0.0086 & -0.0436 & & & \\
\hline $\mathrm{P} 2 \mathrm{P}$ & -0.0366 & -0.0328 & -0.0665 & 0.0687 & -0.0808 & -0.2891 & 0.7017 & & \\
\hline P3P & -0.0348 & -0.0572 & 0.1028 & 0.3334 & 0.1064 & 0.1963 & 0.0650 & 0.0750 & \\
\hline TAMP & 0.0057 & -0.0460 & -0.1998 & -0.0300 & -0.2604 & -0.5094 & -0.0092 & 0.1712 & -0.1145 \\
\hline
\end{tabular}

Fonte: os autores. 
A Tabela 3 faz uma comparação entre os sinais esperados e obtidos. Nos indicadores de liquidez, L1P apresentou sinal positivo, indicando que bancos mais líquidos, provedores de recursos no mercado financeiro brasileiro, securitizam mais que os bancos menos líquidos. Por outro lado, no caso de L2P, nota-se que quanto menor for esse indicador, sinalizando maior liquidez, maior será a propensão a securitizar. Nesse grupo, o único indicador que apresentou sinal igual ao esperado foi o L3P, demonstrando uma relação negativa entre o índice e a propensão à securitização. Ao considerar o risco de crédito, o sinal obtido confirma que, quanto maior o risco, R1P, maior a propensão a utilizar a securitização.

No fator capital regulatório, C1P confirmou a expectativa de que bancos que apresentam menores índices de capital regulatório tendem a securitizar mais. Contrariando essa expectativa, em C2P a relação é positiva, ou seja, quanto maior for esta, maior será a propensão a securitizar. Resultados similares foram encontrados por Bannier e Hãnsel (2008) no mercado europeu para ambos os indicadores.

No fator performance, o sinal esperado tanto pode ser positivo quanto negativo. A hipótese é de utilização da securitização para a melhora de indicadores de perfomance e, no segundo, a hipótese é de “apetite por risco”, indicando que os bancos com performance superior são mais ativos no mercado de securitização. Aqui, o P1P aparece como único índice com relação positiva, ou seja, quanto maior ele for, maior será a propensão à securitização. Por outro lado, o P2P e o P3P apresentaram relação negativa, sinalizando que no mercado brasileiro quanto maior a performance, menor será a propensão à securitização. No mercado espanhol, Cardone-Riportella, Samaniego-Medina e Trujillo-Ponce (2010) encontraram uma relação positiva nesses indicadores, resultados similares aos apresentados por Bannier e Hãnsel (2008) para o mercado europeu.

Por fim, avaliando o tamanho (TAMP), a relação é positiva, o que indica que bancos maiores têm maior propensão à securitização do que bancos menores, sinalizando possíveis ganhos de escala nos bancos maiores nessas operações. 
Tabela 3 - Sinal esperado e sinal obtido na regressão

\begin{tabular}{|c|c|c|}
\hline Variáveis & Sinal esperado & Sinal da regressão \\
\hline \multicolumn{3}{|l|}{ Liquidez } \\
\hline Relação interbancária (L1P) & $(-)$ & $(+)$ \\
\hline Operações de crédito líquidas/Depósitos e obrigações de C.P. (L2P) & $(+)$ & $(-)$ \\
\hline Ativos líquidos/Depósitos e obrigações de C.P. (L3P) & $(-)$ & $(-)$ \\
\hline \multicolumn{3}{|l|}{ Risco de crédito } \\
\hline PCLD/Total de operações de crédito (R1P) & $(+)$ & $(+)$ \\
\hline \multicolumn{3}{|l|}{ Capital regulatório } \\
\hline Índice de Basiléia (C1P) & $(-)$ & $(-)$ \\
\hline Capital/Ativo total (C2P) & $(-)$ & $(+)$ \\
\hline \multicolumn{3}{|l|}{ Performance } \\
\hline Retorno sobre o ativo - ROA (P1P) & $(+/-)$ & $(+)$ \\
\hline Retorno sobre capital próprio - ROE (P2P) & $(+/-)$ & $(-)$ \\
\hline Índice de custo sobre a receita - CIR (P3P) & $(+/-)$ & $(-)$ \\
\hline \multicolumn{3}{|l|}{ Variável de controle } \\
\hline Tamanho do banco (TAMP) & $(+)$ & $(+)$ \\
\hline
\end{tabular}

Fonte: os autores.

A seguir, foram testados diversos modelos resultantes da combinação de todas as variáveis entre si, defasadas em um período, para evitar problemas de endogeneidade e poder captar a dinâmica do modelo. Cada equação testada continha apenas um indicador de cada grupo - liquidez, risco, capital regulatório, performance e tamanho - para evitar problemas de multicolinearidade. Para selecionar o melhor modelo, foram considerados os critérios de comparação Akaike, Schwarz e Hannah-Quinn, e as estatísticas de erro RMSE, MAE, MAPE e Theil. A equação a seguir mostra o melhor modelo:

$$
Y_{i, t}=-1,02-0,42 L 3 P_{i, t-1}+0,16 R 1 P_{i, t-1}+0,23 C 2 P_{i, t-1}-0,18 P 3 P_{i, t-1}+0,20 T A M P_{i, t-1}
$$

A variável performance P3P teve baixa relevância estatística. O teste da Razão de Verossimilhança para variáveis omitidas LR $=2.109284[0.1464]$ confirma a hipótese nula de que inserir a variável performance no modelo não é estatisticamente significativo. A seguir, testou-se um modelo sem a variável performance, resultando em perda de significância para a variável risco, observado na Tabela 4. O teste $L R=1,53[0,21]$ confirma o resultado e essa variável também é excluída nessa etapa. Dessa forma, o modelo final passa a ser dado por: 
Tabela 4 - Modelo logit final

\begin{tabular}{lllll}
\hline Variáveis & Coeficientes & Desvio padrão & Estatística Z & Prob. \\
\hline C & -1.0195 & 0.0920 & -11.0732 & 0.0000 \\
Liquidez (L3P) & -0.4294 & 0.1488 & -2.8849 & 0.0039 \\
Capital (C2P) & 0.2434 & 0.1178 & 2.0657 & 0.0388 \\
Tamanho (TAMP) & 0.2214 & 0.1024 & 2.1602 & 0.0307 \\
\hline
\end{tabular}

Fonte: os autores.

Esse modelo considera apenas a influência da liquidez e do capital regulatório como fatores de impulso para a securitização no setor bancário. A liquidez se mostrou com maior influência na probabilidade de um banco securitizar, sendo essa relação negativa. Nesse caso, o impacto do aumento de uma unidade na medida de liquidez gera um aumento de 0,65 na securitização. Esses resultados são similares àqueles encontrados por Cardone-Riportella, Samaniego-Medina e Trujillo-Ponce (2010) no mercado espanhol, por Cerrato et al. (2012) no Reino Unido e por Agostino e Mazzuca (2008) na Itália. Nesses mercados, os dados demonstram que fatores relacionados à liquidez exerceram maior influência nos programas de securitização.

Interessante observar que os resultados corroboram a teoria pós-keynesiana da firma bancária, considerando que, em razão das expectativas sobre um futuro incerto, as instituições financeiras acabam tendo preferência pela liquidez, adequando seu portfólio para conciliar a lucratividade com a sua escala de preferência pela liquidez. A distribuição da probabilidade de securitizar se mostrou normal para o período analisado, com média de 0,27. Considerando que a performance não apresentou relevância estatística no modelo, o que poderia ser atribuído às altas taxas de juros praticadas no país, elevando seus resultados, a liquidez entra como principal fator para a utilização da securitização e, automaticamente, gera maiores ganhos para essas instituições.

Destaca-se, nessa análise, que o indicador de capital regulatório que melhor se enquadrou no modelo foi a relação entre Capital e Ativo Total (C2P), e não o Índice de Basiléia (C1P), sendo este segundo o que regulamenta efetivamente as questões relativas ao capital. Com uma análise mais detalhada da amostra, verifica-se que apenas 3 das 643 observações apresentaram Índices de Basiléia inferiores ao mínimo exigido de $11 \%$, e, ainda, para mais de 50\% da amostra, o Índice foi superior à exigência mínima em mais de $60 \%$, ou seja, maior que $18 \%$. Esses resultados podem justificar por que o Índice de Basiléia não foi relevante para o modelo, uma vez que o mercado brasileiro, no período de 2005 a 2012, não teve problemas para se enquadrar ao Basiléia II, e, dessa forma, as instituições financeiras não precisaram recorrer a instrumentos como a securitização para se adaptar às regras. 
O odds ratio, ${ }^{7}$ dado pela razão entre as probabilidades $\frac{p}{1-p}$ é 0,38 , ou seja, a probabilidade de ocorrência do evento “não securitizar” é superior à probabilidade do evento “securitizar”. Por fim, para avaliar a eficácia do modelo, foi realizado o teste de Andrews e Hosmer-Lemeshow, que confirma a relevância do modelo: teste H-L $\chi_{(8)}^{2}=7,548[0,47]$ e Andrews $\chi_{(10)}^{2}=9,143[0,518]$.

Um aspecto interessante a ser avaliado é como esses resultados se modificam diante da crise financeira global de 2007 a 2008, ou seja, será que esta produziu uma mudança no padrão da securitização no mercado bancário brasileiro entre esses dois períodos? Para tanto, inseriu-se uma dummy no modelo, que assume valor $=1$ no período pré-crise (2005 a 2008) e valor $=0$ no período pós-crise (2009 a 2012). Na Tabela 5 apresentam-se os resultados, com os quais foi possível verificar que a variável dummy não tem significância estatística ${ }^{8}$ e não é possível afirmar que a crise financeira global de 2007 a 2008 teve impactos na securitização. O teste de variáveis omitidas confirma essa hipótese, LR = 0.162235 [0.6871].

Tabela 5 - Modelo logit pré e pós-crise

\begin{tabular}{lllll}
\hline Variáveis & Coeficientes & Desvio padrão & Estatística Z & Prob. \\
\hline C & -1.0466 & 0.1145 & -9.1404 & 0.0000 \\
L3P(-1) & -0.4293 & 0.1486 & -2.8887 & 0.0039 \\
C2P(-1) & 0.2459 & 0.1179 & 2.0847 & 0.0371 \\
TAMP(-1) & 0.2279 & 0.1037 & 2.1967 & 0.0280 \\
CRISE & 0.0766 & 0.1899 & 0.4033 & 0.6867 \\
\hline
\end{tabular}

Fonte: os autores.

Com o objetivo de confirmar os resultados obtidos, foram conduzidos testes de robustez similares aos realizados por Agostino e Mazzuca (2008).

Inicialmente, considerou-se a modificação do tratamento dos outliers no modelo. Para tanto, as estimativas foram replicadas excluindo da amostra as observações que apresentaram os 5\% menores e maiores índices de liquidez, variável que mostrou maior relevância à utilização de securitização. Nesse caso, tem-se uma redução na quantidade de observações, que passa de 643 para 579. As novas regressões ${ }^{9}$ confirmam os resultados obtidos: na primeira equação obteve-se que performance não tem relevância para o modelo. Ao excluir essa variável do modelo, a variável risco passa a não apresentar mais significância estatística, mantendo, então, os índices de liquidez, capital e tamanho do banco como principais indicativos de securitização no setor bancário brasileiro. Os resultados confirmam, ainda, que a liquidez foi o fator 
que exerceu maior influência na probabilidade de um banco optar pela securitização no período de 2005 a 2012.

O segundo teste foi realizado considerando-se todas as variáveis utilizadas neste estudo, em um modelo geral, apresentado por:

$Y_{i, t}=L 1 P_{t-1}+L 2 P_{t-1}+L 3 P_{t-1}+R 1 P_{t-1}+C 1 P_{t-1}+C 2 P_{t-1}+P 1 P_{t-1}+P 2 P_{t-1}+P 3 P_{t-1}+T A M P_{t-1}$

Ele foi reestimado várias vezes até que todas as variáveis que não apresentavam relevância estatística fossem eliminadas. Como resultado final, L3P, C2P e TAMP foram as únicas que restaram no modelo. Em suma, de acordo com a análise empírica, o fator determinante para a securitização no Brasil refere-se à liquidez, seguida pelo capital regulatório. Além disso, a variável de controle tamanho é positiva e significativa estatisticamente, sinalizando que os bancos maiores têm mais estrutura para arcar com os custos envolvidos nessas operações.

\section{CONCLUSÃO}

Com esta pesquisa objetivou-se geral analisar os principais fatores que levaram os bancos brasileiros a utilizarem a securitização no período de 2005 a 2012, além de avaliar o cenário da crise financeira global de 2007 a 2008 e identificar se houve mudanças no padrão da securitização no mercado bancário brasileiro nesse período.

Nota-se que existe diferença estatística para os índices de liquidez, capital regulatório, performance e tamanho entre os bancos que utilizaram securitização e os que não a utilizaram. Os resultados comprovaram a hipótese de que liquidez e capital regulatório são fatores importantes que levaram os bancos brasileiros a utilizarem a securitização. Não é possível confirmar a hipótese de que risco e performance seriam fatores determinantes da securitização no Brasil.

Duas inferências são feitas acerca desses resultados. A primeira é relativa à liquidez como principal fator determinante da securitização no Brasil, confirmando a teoria pós-keynesiana da firma bancária, que considera que, em razão das expectativas sobre um futuro incerto, essas instituições acabam tendo preferência pela liquidez, adequando seu portfólio para conciliar a lucratividade com sua escala de preferência pela liquidez. Uma vez que performance não apresentou relevância estatística no modelo, o que poderia ser atribuído às altas taxas de juros praticadas no país, gerando altos resultados no setor, a liquidez se destaca na adequação de seus portfólios e, consequentemente, como principal fator para a utilização da securitização. 
A segunda refere-se a questões relativas ao capital regulatório, uma vez que a relação entre Capital e Ativo Total teve mais significância estatística no modelo que o Índice de Basiléia, visto que este é o que regulamenta as questões relativas ao capital. Constatou-se que se tem esse resultado pelo fato de os Índices de Basiléia estarem acima das exigências mínimas de 11\%, uma vez que mais de 50\% da amostra apresentaram índices superiores em mais de 60\%, ou seja, maiores que 18\%. Dessa forma, como as instituições financeiras não tiveram problemas para se enquadrar ao Basiléia II, esse fator não foi determinante na utilização de instrumentos de securitização. A variável dummy utilizada para analisar o cenário pré e pós-crise não se mostrou significativa. Esses resultados foram confirmados pelo teste razão de verossimilhança de variáveis omitidas.

Como sugestão para trabalhos futuros destaca-se a ampliação do escopo de securitização para avaliar o tipo de produto utilizado - FIDCs, CRIs, entre outros ou, ainda, o tipo de ativo utilizado como lastro, e se estes exercem alguma influência ou modificam os resultados encontrados. Sugere-se, ainda, uma análise detalhada dos motivos das diferenças encontradas no estudo realizado no mercado brasileiro em relação ao mercado europeu e suas implicações.

Notas explicativas:

\footnotetext{
${ }^{1}$ Essa reforma, além de aumentar a qualidade e a quantidade dos requerimentos de capital e de melhorar a cobertura de risco da estrutura de capital, introduziu elementos macroprudenciais na sua estrutura, objetivando a contenção dos riscos sistêmicos que surgem da prociclicidade e interconectividade das instituições financeiras (BASEL COMMITTEE ON BANKING SUPERVISION, 2010).

${ }^{2}$ Para maiores detalhes sobre a crise financeira global de 2007 a 2008 ver Baker (2008), Brunnermeier (2009), Iannuzzi e Berardi (2012), Pakravan (2011) e Tridico (2012).

${ }^{3}$ São fundos de recebíveis em que a maior parte dos recursos destina-se à aquisição de direitos creditórios.

${ }^{4}$ A securitização afeta a natureza dos bancos por meio de vários canais: proporciona novas fontes para financiamento de oportunidades de investimentos; possibilita o financiamento de novos empréstimos por meio de sua securitização ou de outros empréstimos vigentes; altera a visão tradicional de instituições de depósitos para provedores de liquidez; e oportuniza aos bancos mantererem portfólios mais diversificados, ficando, assim, menos expostos a choques econômicos locais.

${ }^{5}$ Ver Calomiris e Mason (2004); Minton et al. (2004); Karaoglu (2005); Martin-Oliver e Saurina (2007); Uzun e Webb (2007); Agostino e Mazzuca (2008); Bannier e Hãnsel (2008).

${ }^{6}$ Apesar de Bannier e Hãnsel (2008) terem mostrado evidências que a necessidade de melhorar a perfomance levou os bancos europeus a securitizar, Cardone-Riportella, Samaniego-medina e Trujillo-Ponce (2010) salientam que, ao considerar o argumento do "apetite por risco", os bancos que apresentam performance superior devem ser mais ativos no mercado de securitização.
} 


\begin{abstract}
${ }^{7} \mathrm{O}$ odds ratio indica que, ao incrementar uma unidade na variável explicativa, a probabilidade de securitizar (versus não securitizar) aumenta/reduz em um fator. Quando essa razão é igual a 1, indica que a chance de ocorrência do evento é igual em ambos os cenários. Quando esse valor é superior a 1, indica que o evento tem maior probabilidade de ocorrer no primeiro grupo, nesse caso, securitizar. Quando menor que 1, a relação é inversa.

${ }^{8}$ Resultados similares foram encontrados ao modificar o período pré-crise para 2005 a 2007 e pós-crise para 2008 a 2012 e testar novamente o modelo.

${ }^{9}$ Disponíveis mediante solicitação.
\end{abstract}

\title{
REFERÊNCIAS
}

AGOSTINO, M.; MAZZUCA, M. Why do banks securitize? Evidence from Italy. In: Spanish Finance Forum Conference, 16., 2008, Madrid. Proceedings... Spanish Finance Association: Madrid, May 2008.

BAKER, D. The housing bubble and the financial crisis. Real-World Economics Review, i. 46, 2008.

BANNIER, C. E.; HÃNSEL, D. M. Determinants of Europeans bank’s engagement in loan securitization. Discussion Paper, Deutsche Bundesbank, 2008.

BASEL COMMITTEE ON BANKING SUPERVISION. Basel III: A global regulatory framework for more resilient banks and banking systems. Basle: Bank for International Settlements, Dec. 2010.

BAUR, D.; JOOSSENS, E. The effect of credit risk transfer on financial stability. EUR Working Paper n. 21521, Jan. 2006.

BRUNNERMEIER, Markus K. Deciphering the Liquidity and Credit Crunch 20072008. Journal of Economic Perspectives, v. 23, i. 1, p. 77-100, Winter 2009.

CALOMIRIS, C. W.; MASON, J. R. Credit card securitization and regulatory arbitrage. Journal of Financial Services Research, v. 26. p. 5-27, 2004.

CARDONE-RIPORTELLA, C.; SAMANIEGO-MEDINA, R.; TRUJILLO-PONCE, A. What drives bank securitization? The Spanish experience. Journal of Banking and Finance, v. 34, i. 11, p. 2639-2651, 2010.

CATÃO, G.; RODRIGUES, R. N.; LIBONATI, J. J. Securitização de recebíveis no setor bancário brasileiro: um estudo empírico. Revista Brasileira de Finanças, 2009. 
CATÃO, G. Securitização de recebíveis no setor bancário brasileiro: um estudo multicaso. 2006. 99 p. Dissertação (Mestrado em Ciências Contábeis)-Programa Multi-institucional e Inter-Regional da Universidade de Brasília, da Universidade Federal da Paraíba, da Universidade Federal de Pernambuco e da Universidade Federal do Rio Grande do Norte, João Pessoa, 2006.

CEBENOYAN, A. S.; STRAHAN, P. E. Risk Management, Capital Structure and Lending at Banks. Wharton Financial Institutions Center Working Papers n. 2-9, Oct. 2001.

CERRATO, M. et al. Why do UK banks securitize? Discussion Paper Series: University of Glasgow. Department of Economics, 2012.

COMMITTEE ON THE GLOBAL FINANCIAL SYSTEM. The role of ratings in structured finance: issues and implications. BIS Quartely Review, Jan. 2005.

DUFFIE, D. Innovations in credit risk transfer: implications for financial stability. BIS Working Papers n. 255, July 2008.

FERNANDES, M. P. O mercado de securitização no Brasil e suas fontes de valor. 2010.52 p. Dissertação (Mestrado Profissional)-Fundação Getúlio Vargas, São Paulo, 2010.

GOLDBERG, M. B. A securitização de recebíveis e seus impactos no valor das originadoras: evidências do mercado brasileiro. 2011. 48 p. Dissertação (Mestrado em Economia)-Fundação Getúlio Vargas, São Paulo, 2011.

IANNUZZI, E.; BERARDI, M. Global financial crisis: causes and perspectives. EuroMed Journal of Business, v. 5, i. 3, p. 279-297, 2010. Disponível em: <http:// dx.doi.org/10.1108/14502191011080818>. Acesso em: 13 abr. 2012.

KARAOGLU, N. E. Regulatory capital and earnings management in banks: The case of loan sales and securitizations. Working Paper: FDIC Center for Financial Research, Feb, 2005.

LAUREANO, G. L. Sale of credit portfolio and risk: the case of financial institutions in Brazil. 2009. 86 p. Dissertação (Mestrado em Administração de Empresas)Fundação Getúlio Vargas, São Paulo, 2009. 
LEE, H. J. Essays on asset securitization, bank production costs and the credit card market. 2003. 137 p. Tese (Doutorado em Economia)-University of California, Berkeley, 2003.

LOUTSKINA, E. The role of securitization in bank liquidity and funding management. Journal of Financial Economics, p. 663-684, 2011.

LUXO, J .C. A. O impacto da securitização de ativos nos indicadores financeiros e nos betas das empresas. 2007. 234 p. Tese (Doutorado em Administração)-Universidade de São Paulo, São Paulo, 2007.

MARTIN-OLIVER, A.; SAURINA, J. Why do banks securitize? Spanish Finance Forum Conference, 15., 2007, Palma da Maiorca. Proceedings... Palma de Maiorca: Spanish Finance Association, Nov. 2007.

MASON, J. R.; ROSNER, J. How resilient are Mortgage Backed Securities to Collateralized Debt Obligation market disruptions? Working paper series. Feb. 2007.

MINTON, B.; SANDERS, A.; STRAHAN, P. Securitization by banks and finance companies: efficient financial contracting or regulatory arbitrage? Working Paper: Ohio State University, 2004.

OLIVEIRA, C. M. R. Determinantes de spreads de ativos securitizados: uma avaliação de fundos de investimento em direitos creditórios. 2012. 55 p. Dissertação (Mestrado em Economia)-Escola de Economia de São Paulo, Fundação Getúlio Vargas, São Paulo, 2015.

PAKRAVAN, K. Global financial architecture, global imbalances and the future of the dollar in a post-crisis world. Journal of Financial Regulation and Compliance, v. 19, i. 1, p. 18-32, 2011. Disponível em: <http://dx.doi. org/10.1108/13581981111106149>. Acesso em: 13 abr. 2012.

PINHEIRO, F. A. P. Securitização de recebíveis - uma análise dos riscos inerentes. 2008. 186 p. Dissertação (Mestrado em Administração)-Universidade de São Paulo, São Paulo, 2008.

PULINO, M. V. Z. O custo de capital em operações de securitização de recebíveis de empresas não financeiras por meio da emissão de cotas de Fundos de Investimento em Direitos Creditórios - FIDCs. 2008. 73 p. Dissertação (Mestrado em Administração de Empresas)-Fundação Getúlio Vargas, São Paulo, 2008. 
SILVA, R. R. Os Fundos de Investimento em Direitos Creditórios (FIDCs) como uma alternativa ao financiamento de micro e pequenas empresas: uma análise do mercado de crédito brasileiro. 2006. 85 p. Dissertação (Mestrado em Economia)Universidade de São Paulo, Ribeirão Preto, 2006.

TRIDICO, P. Financial Crisis and global imbalances: its labour market origins and aftermath. Cambridge Journal of Economics, i. 36, p. 17-42, 2012.

UZUN, H.; WEBB, E. Securitization and risk: Empirical evidence on US banks. The Journal of Risk Finance, v. 8, p. 11-23, 2007.

Como citar este artigo:

ABNT

FERABOLLI, Cristina; MORAIS, Igor Alexandre Clemente. Modelagem estatística com foco na motivação dos bancos que securitizaram no Brasil entre os anos 2005 e 2012. RACE, Revista de Administração, Contabilidade e Economia, Joaçaba: Ed. Unoesc, v. 15, n. 2, p. 579-600, maio/ago. 2016. Disponível em: <http://editora. unoesc.edu.br/index.php/race>. Acesso em: dia/mês/ano.

APA

Ferabolli, C., \& Morais, I. A. C. (2016) Modelagem estatística com foco na motivação dos bancos que securitizaram no Brasil entre os anos 2005 e 2012. RACE, Revista de Administração, Contabilidade e Economia, 15(2), 579-600. Recuperado em dia/mês/ano, de http://editora.unoesc.edu.br/index.php/race 
